\title{
The changing graduate labour market: analysis using a new indicator of graduate jobs
}

Francis Green* and Golo Henseke

\author{
* Correspondence: francis.green@ \\ ucl.ac.uk \\ LLAKES Centre, UCL Institute of \\ Education, London, UK
}

\begin{abstract}
This paper examines differentiation in the recent evolving graduate labour market in Britain. Using a novel statistically derived indicator of graduate jobs, based on job skill requirements in three-digit occupations obtained from the British Skills and Employment Survey series, we analyse trends in the labour market between 1997/2001 and 2006/2012. The indicator performs better than other indicators in validation tests, could be applied flexibly in other contexts, and is available in the Additional file 1. We find that the massive influx of graduates into the labour force has been absorbed with no increase in overeducation. However, the returns to graduation have become more dispersed, with those at the upper quartile of the residual distribution increasing, while those at the lowest quartile have fallen. The wage gap between matched and overeducated graduates increased by 11 log points. Using the British Household Panel Study, we find that the persistence of overeducation status did not change but for non-employed male graduates moving into employment, the chances of entering a graduate job decreased.
\end{abstract}

JEL Classification: J21, J24, J3

Keywords: Higher education, Wages, Skills, Overeducation, Tertiary education

\section{Introduction}

Following the massification of higher education (HE) and subsequent expanded supply of tertiary-educated labour, there is growing concern in public discourse that the supply of graduates is outstripping the number of "graduate jobs" with negative consequences for skills utilisation, pay, and career opportunities. So far, studies suggest that in many countries, the returns to tertiary education have risen or held steady, implying that the rising demand has at least till recently kept pace with the supply (e.g. Machin and McNally 2007), while in only a few countries such as Hong Kong (Lui and Suen 2005) have the returns fallen. There is some evidence, however, of differentiation in the returns along varied dimensions (e.g. Martins and Pereira 2004; Hoekstra 2009; Green and Zhu 2010; Altonji et al. 2012; Figueiredo et al. 2013; Lindley and Machin 2014). Differentiation reflects a combination of within-group skill heterogeneity and disequilibrium in the graduate labour market, consistent with a range of labour market theories (McGuinness 2006). This paper examines changing differentiation in the recent

(C) 2016 The Author(s). Open Access This article is distributed under the terms of the Creative Commons Attribution 4.0 International License (http://creativecommons.org/licenses/by/4.0/), which permits unrestricted use, distribution, and reproduction in any medium, provided you give appropriate credit to the original author(s) and the source, provide a link to the Creative Commons license, and indicate if changes were made. 
evolving graduate labour market in Britain, through the lens of evidence on "graduate jobs" using a new indicator.

Hitherto, discourse on graduate labour markets that focuses directly on supply- and demand-side indicators has been hindered by the lack of a widely accepted, conceptually satisfactory method of classifying occupations as "graduate jobs" or "non-graduate jobs". Existing classifications are used by career advisers, human resource service companies, policymakers, and journalists (e.g. ONS 2013; Scurry and Blenkinsopp 2011; Milburn 2009; Groom 2013), as well as by researchers studying high-skilled labour markets and graduate overeducation. But no consensus exists as to what constitutes a graduate job. Some classifications are conceptually flawed, using tautological indicators, while others are unsuitable for analysing trends over time or rely on a traditional concept that makes no room for upskilling outside the professional and high managerial occupations. This paper contributes a new method of classifying occupations, which is conceptually valid, based as it is on direct evidence of skill use in jobs, and which is therefore responsive to changes in job skills within jobs. Several empirical tests of its criterion validity support its use over other indicators. While we deploy the indicator to analyse recent changes in Britain's high-skilled labour market, it can be used in a wide variety of settings and for multiple purposes.

While changes in tertiary education mismatch might arise from changes in the efficiency of skills matching institutions or from changing within-group skill heterogeneity, current concern tends to focus on the overall balance of the stock of graduates and graduate jobs, supplemented by potential effects from the great recession. The growth of graduate jobs is linked to the rising demand for high skills, as concluded by the substantial research literature on skill-biased and task-biased technological change (e.g. Acemoglu and Autor 2011; Goos et al. 2014). However, questions surround whether the pace of change in demand has been lagging behind the rising graduate supply or indeed whether the growth in high-skills demand has decelerated or even reversed (Beaudry et al. 2016). Adding to public unease surrounding the prevalence of graduate overeducation alongside high costs of HE, its consequences may also be changing. In many countries, occupational upgrading has taken the form of an asymmetric polarisation of employment (Autor et al. 2003; Dustmann et al. 2009; Fernandez-Macias 2012; Salvatori 2015). The relative diminution of middle-tier jobs implies that the experience of being a mismatched (that is, overeducated) graduate could involve an increasing wage penalty relative to matched graduates, as the average quality of jobs below graduate level diminishes, while that of high-skilled graduate jobs rises. With rising graduate unemployment following the Great Recession comes also the fear that more graduates will take up non-graduate jobs and encounter fewer opportunities to progress into graduate jobs.

To assess these concerns in respect of Britain, and to illuminate recent trends in the graduate labour market, the questions we pose in this paper are as follows: what has been happening to the aggregate balance between graduates and graduate jobs? What has been happening to the prevalence of overeducation among graduates over the medium term since the late 1990s? Has there been an increasing differentiation in the returns to HE, and have the negative effects of being overeducated become more severe?

With this new indicator, we find that over the course of approximately a decade from the late 1990s, the number of graduate jobs rose almost as much as the rise in the 
supply of graduates. Moreover, graduate overeducation increased only by a small and statistically insignificant amount. The greater part of the rise in graduate jobs came from an increased prevalence of high-level occupations, but we find also some evidence of occupational re-grading. Nevertheless, we also find increasing dispersion in the returns to tertiary education over the decade and a significant deterioration in the experience associated with being overeducated, with substantive rises in the wage penalty and no decline in the persistence of overeducation. Together, the findings imply that, even though the average return to investing in $\mathrm{HE}$ has not fallen, the risk has increased.

In the next section, we examine the concept of a graduate job, consider desirable properties for an indicator, and review existing classifications of graduate jobs. Section 3 describes our data and new classification method. Section 4 provides the British institutional context and presents our findings on the trends in graduate jobs and in graduate overeducation over an interval of just over a decade. Section 5 takes up the issue of the penalty facing overeducated graduates and whether this has been changing over the same period. Section 6 examines changes in the labour market transitions of graduates with respect to their overeducation status.

\section{The concept and indicators of a "graduate job"}

Despite its widespread use, the idea of a "graduate job" is a contentious one in labour economics. Since this concept is central to the picture of the graduate labour market presented in this paper, we begin in this section with a review of the concept's advantages and problems and of the indicators used to capture it.

We conceive a graduate job to be one where a substantial portion of the skills used are normally acquired in the course of higher education, including many of the activities surrounding it, and of its aftermath-the years after higher education when skills are acquired in work through graduates' acquired faculty for learning them. ${ }^{1}$ This concept is inherently not very precise nor does it imply that the skills acquired in higher education and those used in jobs are identical.

In this context, four points are important to note. First, some benefits of higher education are wider than for work. Moreover, some benefits are external, accruing to people other than those being educated. Neither of these benefits are captured in graduate jobs, which are inherently built upon private employment-related benefits. Second, benefits accrue, not just from formal learning and certification but through the higher education experience, including leaving home, encountering those with different viewpoints, and learning about alternative biographies. Third, the skills acquired in higher education are a mix of subject-specific skills and more generic skills. UK graduates in the 2005 REFLEX survey of recent graduates across Europe reported the following main competencies acquired through higher education 5 years earlier: analytical thinking (34\% of respondents), performance under pressure (28\%), ability to work productively with others ( $26 \%$ ), mastery of own field or discipline (26\%), ability to rapidly acquire new knowledge (24 \%), and writing skills (22 \%) (Little et al. 2008, pp. 3233). In contrast, skills that relate to the mobilisation and orchestration of others' competences appear to benefit less directly from formal teaching during tertiary education but develop, for example, during study-related work placements or civic participation (Allen and van der Velden 2011, Chap. 6). Fourth, the skills for graduate jobs could 
have been acquired at other sites, such as family or work, independently of higher education. Indeed, it is hard to be sure exactly when and where skills are acquired. Many graduates report having acquired relevant skills during work experiences either before or during their HE courses, though the proportions that do so are rather lower in the UK than elsewhere in Europe (Little et al. 2008, p. 35). Some skills may be acquired prior to work and HE entry.

The chief advantage of a graduate job classifier for occupations is that it can be applied wherever occupation is coded up. ${ }^{2}$ First, though, a word of caution is necessary. However good the classifier, there will remain an inevitable fuzziness in any simple two-way classification of jobs as graduate or otherwise. There is variation in the level and types of skills deployed, even at high levels of disaggregation; moreover, job skill requirements are in multiple domains, and neither absolute nor precise, so that substitution among variously skilled co-workers is usually possible. ${ }^{3}$ Any two-way classification must assume, therefore, that fuzziness at the threshold, and the heterogeneity among graduate jobs, are not so extensive as to generate unacceptable measurement error or outweigh the value of having a simple indicator for analysing graduate labour markets.

A graduate job indicator should reflect the concept as closely as possible. Its method should also be transparent, replicable, and flexible enough to be applied in a variety of settings. How do existing indicators fare in these respects? Many existing indicators of graduate jobs are inadequate, however, not so much because of a fuzzy threshold but because they are inflexible, loosely connected to high-skills utilisation, or inappropriately defined from the supply side (with attendant risks of pointless tautology: "graduate jobs are the jobs that graduates do").

Thus, some writers utilise indicators that are essentially driven by the proportion of graduates in the occupation (e.g. Mason et al. 2009; Wilton 2012). This approach follows the tradition that measures unit group skill requirements by the mode or median educational level of the individuals doing them, in order to contribute to an indicator for overeducation (Verdugo and Verdugo 1989). Perhaps the most sophisticated approach of this kind was that of Elias and Purcell (2004a, 2004b), whose classification distinguished between different kinds of graduate jobs. Distinction was made between "traditional", "modern", and "new" graduate jobs, according to age cohorts and the differences between them. Use was also made of source materials on job titles to identify "niche" graduate jobs. A similar approach has been applied in Portugal (Figueiredo et al. 2011). This method was a step forward because it highlighted the breadth of the types of skilled work that graduates were doing, moving away from the traditional definition that was starting to look outdated. Nevertheless, the reliance on supply to indicate demand became increasingly questionable following the massification of higher education (Elias and Purcell 2013).

An alternative indirect route to identifying graduate jobs is via the assumption that graduate jobs are those where there is a high return to college education. It has been argued that this method is preferable because it identifies graduate skill requirements "objectively" via the market signal of wages. Using this method, Gottschalk and Hansen (2003) classified jobs as "college" or "non-college" and found that the proportion of college-educated workers in non-college jobs declined during the 1980s and early 1990s, attributing this to skill-biased technological change; Cardoso (2007) found a similar story for Portugal over 1986 to 1999, while O'Leary and Sloane (2014) find the 
opposite story for Britain in the 2000s. Yet this method also has its problems, including the likelihood that within-occupation estimates of returns to education are biased because of selection by unobserved factors into occupations; if there is differential bias between occupations, this will affect the classification. A further issue could arise from one potential use of a graduate job indicator: if graduate overeducation (defined via the classifier) is interpreted as a measure of market disequilibrium, it could be utilised as a predictor (alongside other factors) of future wage changes, but such a use would be problematic when the index is constructed using wage data. To capture changing education requirements, Neumark et al. (2013) adopt a mixed strategy that uses the trend in within-occupational educational attainments, alongside a validity check on their wage effects; they show that this generates substantively different forecasts for the future demand for high-skilled jobs in the USA, as compared with those of the Bureau of Labor Statistics' estimates derived from O'NET and expert-based data.

Although no indicator can be expected to be a perfect reflection of the concept of a graduate job, indicators derived directly from measures of skills use are closest to the concept and therefore preferable. Some studies in this mould have stuck with a broad occupational classification. The traditional association linking graduates with major occupation group 2 (professional occupations) is now normally extended to embrace, as well, major group 1, covering all the unit groups involved in management. Thus, major groups 1 and 2 (i.e. managers and professionals) are regarded as the "high-status" occupations (Bukodi and Goldthorpe 2011; Macmillan et al. 2015). But, given the possibility that many other jobs outside these two groups are now utilising graduates' skills, for a classification of graduate jobs, it is necessary to go beyond the traditional notion of high status. Our preference for a direct skills-based indicator is consonant with the development in several countries of task-based analyses of labour markets (Autor et al. 2003; Gathmann and Schönberg 2010; Green 2012). One approach has been to draw on US-based job classifications based on expert-derived information about skills requirements. Thus, Chevalier and Lindley (2009) use the 1991 Dictionary of Occupational Titles (DOT) definition of graduate jobs which augments the definition beyond managers and professionals to include nurses, midwives, and IT associate professionals. Since the DOT and its successor the O'NET classifications tend not to be fully updated except at long intervals, inevitably, this method of classifying graduate jobs is not ideal for identifying where jobs are upskilled and become graduate jobs or indeed where new jobs come into being that do not fit into old classifications. As Neumark et al. (2013) show, using a mixed strategy that uses the trend in within-occupational educational attainments alongside a validity check on their wage effects, forecasts that rely on static O'NET, and expert-based data could significantly underestimate the future demand for high-skilled jobs.

Best by far among skill-based classifications of graduate jobs in Britain is a relatively new index, termed "SOC(HE)2010_EP"4 (Elias and Purcell 2013). Using as their base the Quarterly Labour Force Surveys in 2011(Q1)-2012(Q3), they scored each unit group by making a qualitative assessment about the use of three types of skills deemed graduate skills-what they term "specialist expertise", "orchestration expertise", and "communications expertise"-in the most frequently occurring job titles within each group. Where the scores exceeded a threshold in any of these three categories, the unit groups were classified to be graduate jobs. In effect, this is an "expert"-based 
classification method by an interpreter of job titles. A similar method has been used in other countries to allocate "most appropriate" educational requirement levels to occupations (e.g. Baert et al. 2013). This method has the key advantage that it is based on the skills used in jobs and not on the qualifications, gender, age, or any other characteristics of the jobholders. Yet, how expert judgements are made and how far they are embedded in labour regulations lack some transparency: it would be hard for others, therefore, to replicate the SOC(HE)2010_EP classification. Moreover, no direct evidence is obtained as to the level of qualification that may be required to do jobs competently. As to the utility of SOC(HE)2010_EP, it is also a disadvantage that we do not have equivalent, commensurate classifications available for earlier occupational codes before SOC2010, which would be needed for long-term trend analyses. Repeated, regular, and consistent expert-based assessments would come at considerable cost.

In the new method we propose below, we follow the same principle of using only skills-based information. The difference is that, in place of expert assessment of job titles, we directly access jobholders' reports of job requirements. The assumption underlying this choice is the same as that underpinning many task-oriented surveys around the world and now utilised in the OECD's Survey of Adult Skills (OECD 2013): jobholders are likely to be the most precise informants about their jobs. Building on this presumed advantage, jobholders' reports of educational requirements could be used to describe individual jobs: this is the basis for many studies, including those from the REFLEX studies noted above. Yet, despite the informational advantage, jobholders' perspectives (sometimes referred to as the "subjective" method) could be open to some self-esteem bias. Green and James (2003) found evidence of some differences between employees' and their line managers' reports, though they also found task items to be reasonably reliable. Similar indicators were used following validation tests in the OECD's Survey of Adult Skills, the German National Educational Panel Study (Matthes et al. 2014), or the World Bank's STEP Skills Measurement Program (Pierre et al. 2014). As described in more detail below, we use skills requirement data in combination with the self-reported education requirement data, to derive an index of the latent "graduate skills requirement". This index captures the educational requirement that is warranted by the high skills used in the job. The index is then aggregated from the individual level to that of the three-digit SOC code.

In addition to avoiding potential self-esteem biases in individuals' responses about the educational requirements of their jobs, our method avoids the use of hard-toreplicate expert judgements and deploys an observer-neutral classification procedure based on relatively simple statistical classification methods. Our method is also updatable, transferable to new or old occupation coding frames, and applicable across countries.

\section{Data and classification method}

\subsection{Data}

The primary requirement for classification is a set of data on skills use in all types of jobs, alongside occupational coding. An efficient and reliable way to collect such information is via a representative survey of the employed labour force. The Skills and Employment Survey (SES) series comprise nationally representative sample surveys, 
collected at intervals of 4-6 years, of employed individuals in Britain aged 20-60 years old (although the 2006 and 2012 surveys additionally sampled those aged 61-65). For the purposes of this paper, we use the surveys in 1997, 2001, 2006, and 2012, all of which collected detailed information about skills requirements. ${ }^{5}$ By design, the surveys are representative of filled jobs but not open vacancies.

In order to undertake some consistent dynamic analyses of graduate overeducation over two separate intervals, we also make use of panel data for employed workers from the British Household Panel Survey (BHPS) and its successor Understanding Society. The BHPS was a long-running representative panel study of approximately 10,000 adults (aged 16+) in Britain with comprehensive annual information on socioeconomic circumstances between 1991 and 2008 (University of Essex 2010). Its successor, the United Kingdom Household Longitudinal Study (UKHLS), incorporated the original BHPS sample since its second wave in 2009 (University of Essex 2014).

We also make use of the Quarterly Labour Force Survey (QLFS), to which the classifier can be applied. The QLFS, which is the prime source of official employment and unemployment data for the Office for National Statistics, ${ }^{6}$ has the advantage of covering a large sample, enabling descriptive analyses of occupations at a more disaggregated level than with the other surveys used in this paper.

\subsection{The graduate job classifier}

Our classifier involves a three-step procedure. In the first step, individual-level job data are used to compute a latent "Graduate Skills Requirement" (GSR) index. Second, we average this univariate index across three-digit occupation groups. The third and final step consists of using the averaged index to classify unit groups as graduate or nongraduate occupations by $k$-medians clustering.

In step 1, following the principles outlined in Section 2, the GSR is derived as a latent index $\left(D^{\prime \prime}\right)$ determining the predicted probability that a tertiary education qualification is required to do the job. We run a probit model of $D^{\prime \prime}$ on multiple indicators of highskills use obtained from the task indicators and other variables in the data. The predicted values of the model recover the variation in $D^{*}$ that is due to differences in skills requirements. The observed binary variable, $D$, is measured as follows. Workers are asked which qualifications would be required by a current applicant to get the job they are doing and, in a follow-up question, how far (on a four-point scale) they judge that qualification to be necessary to do their job competently (with the emphases included in the questions). This information is then coded with the value 1 if a worker reports both, to the first question, that a qualification at level 4 in the national in the UK national qualifications framework (degree or equivalent) or above is required to get the job and, to the second question, that it is deemed "essential" or "fairly necessary" for doing it competently, and 0 otherwise. ${ }^{7}$

This approach is conceptually similar to methods applied in health economics to purge self-reported health from reporting error (e.g. Jürges 2007). Here, the error that is purged is random individual-level variation in reporting bias of educational requirements. However, not all subjective biases are definitely removed through this approach: if for some reason respondents were to overstate the importance of some high-level skill, the GSR would be correspondingly overstated. Thus, as with other task-based 
analyses, the method assumes that the reliability of task-based reporting is of sufficient quality. Comparability across countries, for example, could be limited if the "importance" of certain tasks were reported in culturally affected ways. ${ }^{8}$

Predictors for the probit model of $D^{\prime \prime}$ comprise multiple indicators of high-skills use:

i. A dummy variable indicating that computers are important and used at a high level-either "complex" (e.g. for computer-aided design or statistical analysis packages) or "advanced" (e.g. using computer syntax).

ii. The SES series has collected consistent data on the importance in jobs of a large range of generic tasks since 1997 (Green 2012). We deploy a subset of task scores thought to be needed at a high level in graduate jobs: literacy skills (e.g. writing long reports), professional communication skills (e.g. making speeches or presentations), supervisor responsibilities, self-planning skills (that is, ability to autonomously plan one's work), and specialist knowledge. Each component is defined as a binary variable which is 1 if the generic skill is required at a high level and 0 otherwise.

iii. In addition to high-level generic task requirements, graduate jobs are also characterised by higher complexity and greater variety of work tasks; therefore, we have added dummy variables indicating a high level of variety and a low level of repetitiveness.

iv. A broad indication of a graduate skill level in some jobs is whether the job requires jobholders to have had a long-lasting formal training for the type of work they do. We thus include a binary measure of the prior training received for the type of work on a worker's current job. The dummy variable is 1 if a worker reports having received over 2 years of training.

v. Finally, we also make use of the structure of the Standard Occupational Classifications (SOC) itself. The SOC groups jobs in terms of required skill level, field of knowledge, and type of work together into occupational groups, into four levels of disaggregation with decreasing within-group heterogeneity, ranging from major occupational group (one-digit) to unit group (four-digit) (Elias and McKnight 2001). We exploit this construction principle to calculate an index (DN) of the degree requirement in jobs "similar" to the worker's current position. Similar jobs are defined by all observations within the same minor group (three-digit). Formally,

$$
\mathrm{DN}_{i}=\frac{\sum_{k=1}^{K} D_{k(i)}}{K(i)}
$$

where $k(i)$ describes the set of $K$ jobs that form the neighbourhood of job $i$ and $D_{k(i)}$ represents whether a degree is required to perform job $k$ in worker $i$ 's neighbourhood.

We make no claim that these predictors exhaustively cover the range of skills that could be required in graduate jobs. We have tested the sensitivity of our classification to introducing further task-based covariates which might be held to be part of a graduate's skills set, such as "instructing, training, or teaching people": the additional tasks proved to have no significant conditional association with the graduate skills requirement, and their inclusion made only small differences to the predicted latent skills 
index. We also explored whether potential reporting differences by age and sex affected the classification, and again, we found no evidence that these demographics mattered over and above the included work tasks for the classification outcome. It is not asserted that each of the above work tasks is always required in a graduate job. Nevertheless, when combined, the variables contribute to a plausible and transparent classification. Coefficient estimates of the model are given in the Additional file 1. From the estimation results, we compute the latent index of Graduate Skills Requirements (GSR) as the predicted probit value.

Next, in the second step, we average the GSR scores across each three three-digit group. In a small number of cases (noted in the Additional file 1), to protect against outliers (individuals with especially idiosyncratic task sets) and to help to minimise noise due to reporting errors and occupation misclassification (e.g. Sullivan 2009), we imputed the derived scores of three-digit occupations (minor groups) with less than ten observations with average values from the two-digit level of the occupational classification (sub-major group). Figure 1 presents the distributions of GSR scores within each major occupation group, using the pooled 2006/2012 data and the SOC2000 occupation codes. The distributions of the average scores follow intuitively sensible patterns across major groups: the scores are highest in major groups 1,2, and 3 and lowest in major groups at the bottom of the classification. The distribution (and subsequent classification) was not sensitive to whether or not we omitted the above imputation procedure for small-celled occupations. Considerable heterogeneity is evident, however, within the major groups.

In the third and final step, we partition the occupations into a group of graduate and non-graduate occupations. Simple clustering techniques are among the most widely

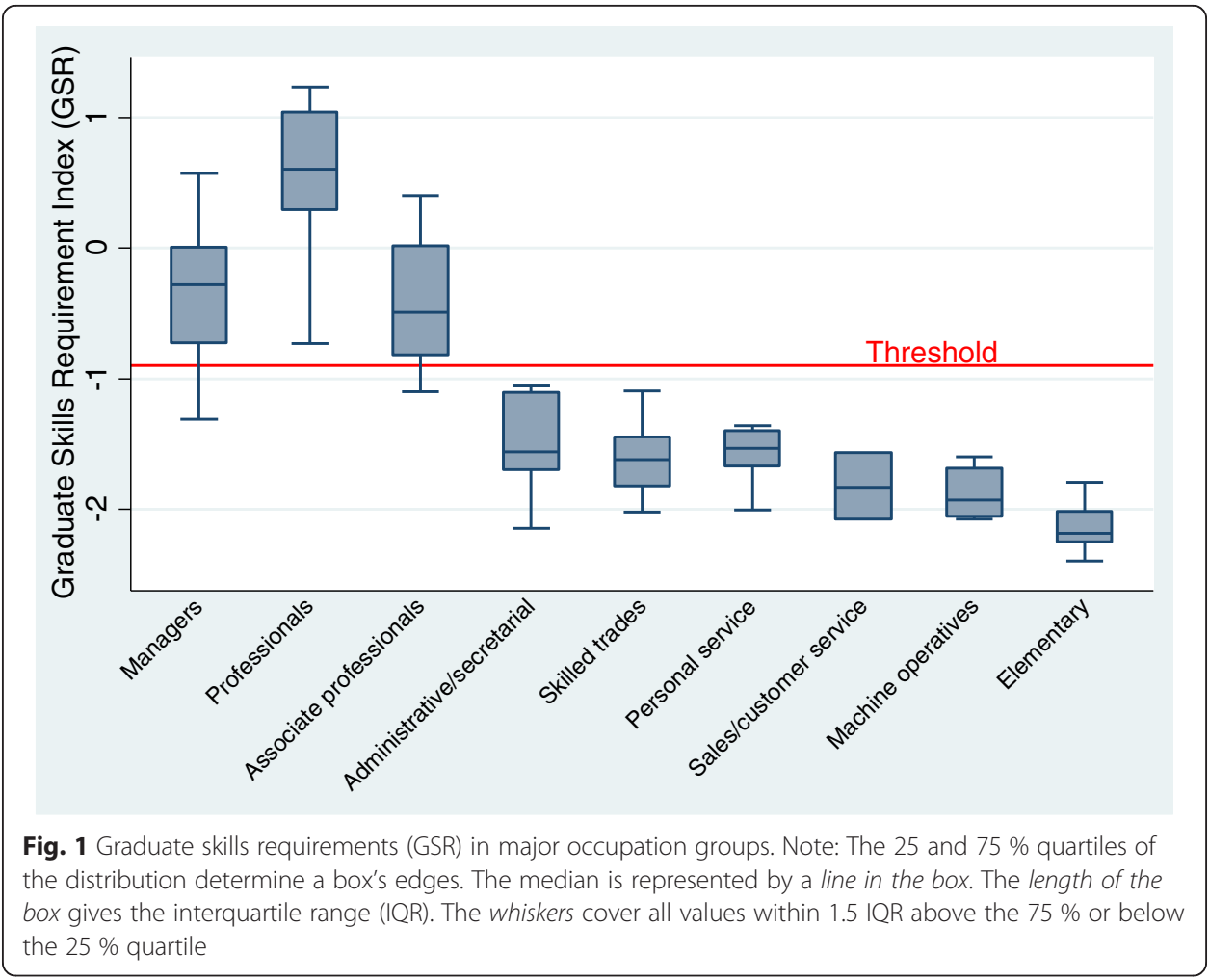


adopted methods to approach the classification problem (Everitt et al. 2011). Since the goal is to derive two distinct non-overlapping groups of occupations, namely graduate and non-graduate jobs, we apply $k$-medians clustering, which is a variant of the wellestablished $k$-means clustering method. The latter is a conventional algorithm that assigns cases (in our case, three-digit occupations) to the nearest cluster such that the squared distances from the cluster's centre are minimised. The $k$-medians algorithm uses the median instead of the mean as the centre of the derived clusters and is therefore better in dealing with outliers in the data.

For any occupational coding system that structures jobs by required skill levels, the clustering process generates two occupational groups with distinct levels of GSR. All occupations which score above (below) the calculated cut-point $(-0.897$ for SOC2000, shown in Fig. $1^{9}$ ) are labelled "graduate job" ("non-graduate job"). We term this new classification "SOC(HE)_GH". The full list of graduate and non-graduate occupations in the first four major groups is given in the Additional file 1, Table A2. With occupations distributed across the whole range of skills scores, there is no sharp distinction between graduate and non-graduate jobs at the margin, and a small number of occupations have GSR scores that are not significantly above (or below) the threshold; these are shown shaded in grey.

\subsection{Criterion validity}

In addition to noting the plausible distribution across major groups, we examined the criterion validity of the SOC(HE)_GH classifier formally against alternative indicators. The comparators were five other classifiers based on the prevalence of graduates in the job, major groups 1 and 2, major groups 1-3, the Gottschalk-Hansen method, and the Elias/Purcell classifier SOC(HE)2010_EP. Since the conceptually best alternative SOC(HE)2010_EP (see Section 2) is available only for SOC2010, we use SES 2012 for these tests and, where the data allow, the four waves of the QLFS in 2013 and 2014 which are also coded in this way. We test predictions, not just within the whole sample (where validity should be easily established) but also just within what we term the "risk zone" of jobs in major occupational groups which are not all in one category, i.e. 1, 3, and 4 , where there is therefore a greater risk of misclassification. We investigated the extent to which SOC(HE)_GH discriminates with respect to the expectation that graduates should receive higher wages in graduate jobs than in non-graduate jobs.

The top panel of Table 1 reports wage regression results using a standard set of controls. SOC(HE)_GH, shown in column 2, is first compared in column 3 with a "naïve" classifier based on the number of graduates in each minor group. Minor groups in which the modal worker had a level 4 education (tertiary) as compared to no education or levels 1 to 3 were classified as graduate occupations. Column 4 is the "traditional graduate jobs" classifier, defined as belonging to the first two major occupational groups. The fifth column is more generous, allowing all major group 3 to be included as graduate jobs. The sixth column deploys and shows the Gottschalk-Hansen classifier, based on the pay premium for tertiary education within each three-digit occupation.

The results confirm that, for graduates, working in a graduate job is associated with a large and statistically highly significant wage premium across all classifications. However, the point estimates and the accuracy of the estimations vary. The proportion of 
Table 1 Wage premium of matched compared with mismatched graduates, by classification method

\begin{tabular}{|c|c|c|c|c|c|c|}
\hline & SOC(HE)2010_GH & $\begin{array}{l}\text { Freq. of } \\
\text { graduates }\end{array}$ & $\begin{array}{l}\text { Major groups } \\
1 \text { and } 2\end{array}$ & $\begin{array}{l}\text { Major groups } \\
1-3\end{array}$ & $\begin{array}{l}\text { Gottschalk- } \\
\text { Hansen }\end{array}$ & SOC(HE)2010_EP \\
\hline \multicolumn{7}{|c|}{ Employees and self-employed_SES 2012} \\
\hline \multirow[t]{2}{*}{ Graduate job } & $0.486^{* * *}$ & $0.435^{* * *}$ & $0.373^{* * *}$ & $0.451^{* * *}$ & $0.438^{* * *}$ & $0.436^{* * *}$ \\
\hline & $(0.041)$ & $(0.043)$ & $(0.042)$ & $(0.041)$ & $(0.043)$ & $(0.041)$ \\
\hline$R^{2}(N=1034)$ & 0.276 & 0.221 & 0.223 & 0.242 & 0.244 & 0.259 \\
\hline \multicolumn{7}{|c|}{ Employees_QLFS 2013/2014 } \\
\hline \multirow[t]{2}{*}{ Graduate job } & $0.524^{* * *}$ & $0.524^{* * *}$ & $0.404^{* * *}$ & $0.535^{* * *}$ & $0.463^{* * *}$ & $0.458^{* * *}$ \\
\hline & $(0.007)$ & $(0.009)$ & $(0.006)$ & $(0.007)$ & $(0.007)$ & $(0.006)$ \\
\hline$R^{2}(N=26,553)$ & 0.347 & 0.271 & 0.294 & 0.342 & 0.303 & 0.320 \\
\hline \multicolumn{7}{|c|}{ Employees and self-employed in major groups 1, 3, and 4-SES 2012} \\
\hline \multirow[t]{2}{*}{ Graduate job } & $0.397^{* * *}$ & $0.263^{* * *}$ & $0.224^{* *}$ & $0.285^{* * *}$ & $0.362^{* * *}$ & $0.339^{* * *}$ \\
\hline & $(0.071)$ & $(0.077)$ & $(0.100)$ & $(0.064)$ & $(0.065)$ & $(0.076)$ \\
\hline$R^{2}(N=414)$ & 0.204 & 0.132 & 0.141 & 0.149 & 0.203 & 0.193 \\
\hline \multicolumn{7}{|c|}{ Employees in major groups 1, 3, and 4-QLFS 2013/2014 } \\
\hline \multirow[t]{2}{*}{ Graduate job } & $0.335^{* * *}$ & $0.316^{* * *}$ & $0.249^{* * *}$ & $0.332^{* * *}$ & $0.300^{* * *}$ & $0.266^{* * *}$ \\
\hline & $(0.011)$ & $(0.022)$ & $(0.013)$ & $(0.011)$ & $(0.010)$ & $(0.010)$ \\
\hline$R^{2}(N=10,065)$ & 0.265 & 0.204 & 0.231 & 0.250 & 0.258 & 0.247 \\
\hline
\end{tabular}

Note: OLS regression using calibrated survey weights with age, age squared, a gender dummy, and a full set of regional dummies with London as reference category as control variables. In SES, regions refer to the place of residence, whereas regions in QLFS capture the place of work. QLFS sample restricted to interviews in person. Asymptotically robust standard errors are shown in parentheses. All estimated wage premiums are statistically significant at least at the $5 \%$ level. ${ }^{*} \mathrm{p}<.1 ;{ }^{* *} \mathrm{p}<.05 ;{ }^{* * *} \mathrm{p}<.01$. Source: SES 2012, QLFS Q(1)2013-Q(4)2014

the explained variance is lowest for the naïve and traditional classifications. SOC(HE)2010_EP and the Gottschalk-Hansen classifier each do a better job than the naïve and traditional - the explained variance is clearly higher, with the former performing better. However, the statistical indicator SOC(HE)2010_GH fares best with both data sets.

As expected, restricting the estimation to graduates employed in the "risk zone" of major groups 1,3 , and 4 lowers the model fit across all specifications; but even in this narrower field, the wage premium of matched compared with mismatched graduates is substantive and significant. The ranking across classification methods is similar to the previous one: SOC(HE)2010_GH explains the highest fraction of inter-individual wage differences.

Further criterion validity tests are presented in the Additional file 1, in respect of perceptions of skill underutilisation and participation in skills development. Overall, we found that SOC(HE)_GH meets the criterion validity tests well, in almost all cases better than all the other classifiers, whether for the whole sample or for just the "risk zone". ${ }^{10}$

\section{The growth of graduate jobs and graduate overeducation in Britain}

Despite a substantial research literature on overeducation and skills underutilisation, relatively few studies have assessed trends over time (Green 2013, p. 131). Britain's graduate labour market is similar to many other countries' modern labour markets, which for the last two decades have been fed by ongoing rapid inflows of tertiaryeducated students. In Britain's case, the major surge in participation began at the end 
of the 1980s (see Fig. 2). Despite the imposition of fees in England and Wales in 1998 and some levelling off in the 2000s, the participation rate exceeded by far that of earlier generations, with the consequence that the graduate stock continued to rise. Britain's younger adult population is somewhat distinctive, however, in having a relatively low skills base and unequal skills base, according to the OECD's Survey of Adult Skills (OECD 2013; Green et al. 2015; Kuczera et al. 2016). On the demand side, Britain is characterised by relatively flexible labour markets, including low levels of employment protection and waning union influence, though with a full set of anti-discriminatory regulations and a national minimum wage. It has been highly open to foreign investment and has shown generally rising skill utilisation since the 1980s (Felstead et al. 2013).

It is in this context that we examine our research questions. Underpinning our analysis is an implicit dynamic model of supply and demand in the graduate and nongraduate labour markets, with imperfect matching. This section examines the growth of graduate jobs, juxtaposed against the growth of the stock of graduates. To provide sufficient cases while allowing for the emergence of new graduate jobs, we pool SES waves 1997 and 2001 to make one data point, and 2006 and 2012 for another, with an age range 25-60. For each data point, we derive the appropriate classifier. We thus present an aggregate picture of medium-run change over the period 1997/2001 to 2006/2012, encompassing the possibility of some occupations switching their classification over the period as the required skills evolve.

Reflecting the rapid expansion of tertiary education, over the interval 1997/2001 to 2006/2012, the fraction of graduates in the labour force (columns 4 and 5 in Table 2) rose substantially from 30 to $42 \%$. The changes were most pronounced among employed women and in the age group 25-39 years. By 2006/2012, almost half (49\%) of the employed younger labour force had a degree or an equivalent level of educational attainment.

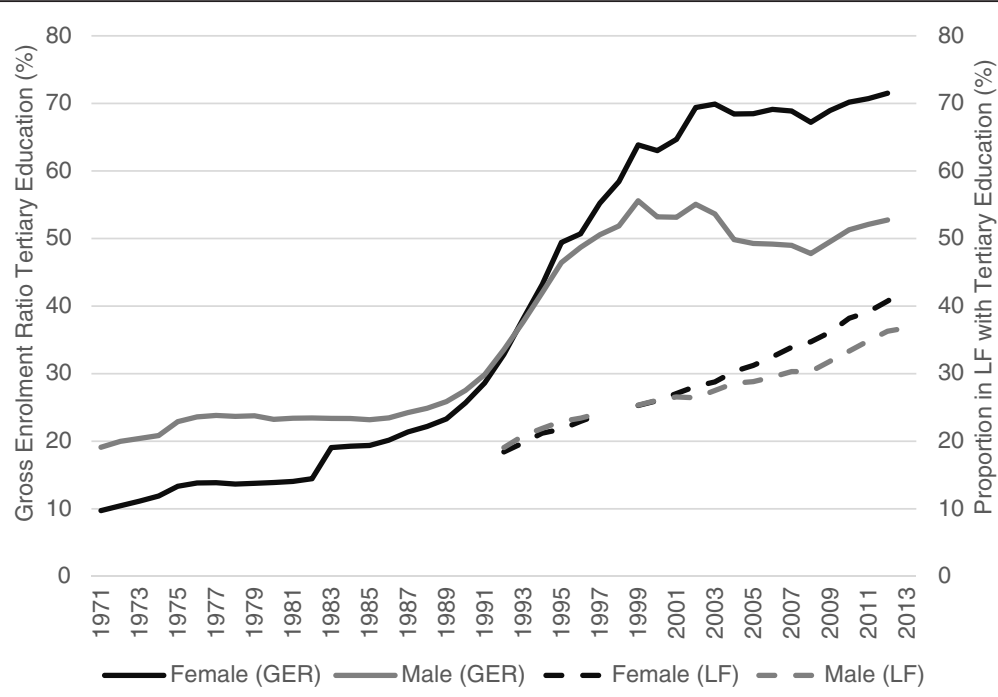

Fig. 2 Participation in tertiary education in Britain: gross enrolment ratio (GER) and proportion in the labour force (LF). Note: The GER in tertiary education is defined as the total enrolment in tertiary education programmes (ISCED 5 and 6), regardless of age, expressed as percentage of the total population in the 5-year age group following on from secondary school leaving. Source: UNESCO, Eurostat 
Table 2 Trends in the graduate labour market between 1997/2001 and 2006/2012 by gender and age (in \%)

\begin{tabular}{|c|c|c|c|c|c|c|}
\hline & \multicolumn{2}{|c|}{ Employed in graduate jobs } & \multicolumn{2}{|c|}{ Graduates in employed labour force } & \multicolumn{2}{|c|}{ Graduates in non-graduate jobs } \\
\hline & $1997 / 2001$ & $2006 / 2012$ & $1997 / 2001$ & $2006 / 2012$ & $1997 / 2001$ & $2006 / 2012$ \\
\hline \multirow[t]{2}{*}{ Men } & 34.1 & 41.1 & 31.4 & 41.7 & 30.5 & 31.7 \\
\hline & $(0.932)$ & $(1.003)$ & $(0.916)$ & $(1.023)$ & $(1.647)$ & $(1.596)$ \\
\hline \multirow[t]{2}{*}{ Women } & 28.3 & 41.1 & 28.3 & 43.1 & 27.2 & 29.1 \\
\hline & $(0.943)$ & $(0.994)$ & $(0.943)$ & $(1.001)$ & $(1.833)$ & $(1.446)$ \\
\hline \multirow[t]{2}{*}{ Ages 25-39 } & 30.3 & 41.9 & 30.4 & 48.9 & 31.9 & 32.0 \\
\hline & $(0.936)$ & $(1.172)$ & $(0.955)$ & $(1.190)$ & $(1.811)$ & $(1.690)$ \\
\hline \multirow[t]{2}{*}{ Ages 40-60 } & 32.5 & 40.5 & 29.5 & 37.5 & 26.5 & 29.0 \\
\hline & $(0.943)$ & $(0.876)$ & $(0.911)$ & $(0.871)$ & $(1.652)$ & $(1.377)$ \\
\hline \multirow[t]{2}{*}{ Total } & 31.5 & 41.1 & 30.0 & 42.3 & 29.1 & 30.5 \\
\hline & $(0.666)$ & $(0.708)$ & (0.659) & (0.719) & $(1.226)$ & $(1.086)$ \\
\hline$N$ (total) & 6436 & 8693 & 6436 & 8693 & 1939 & 3374 \\
\hline
\end{tabular}

Note: Population averages. Standard errors in parentheses. Source: SES 1997-2012

By itself, this transformation of the education level of the workforce in a relatively short time might be expected to have had a notable impact on the graduate labour market. Yet, as shown in columns 2 and 3 of Table 2, Britain also witnessed a marked expansion of graduate jobs over the same period, almost as much as the increase in graduates. In 2006/2012, 41 \% of the employed labour force were employed in graduate jobs, up from $32 \%$ in 1997/2001. The growth in the share of graduate jobs was particularly pronounced for females and among younger workers.

With this growth of the demand side, assuming that there were no radical changes in the efficiency of matching processes, one would expect there to be rather little change over the period in the extent of individual overeducation, despite the rapid diffusion of graduates through the labour force. This turns out to be the case. The proportion of mismatched graduates in the labour market has remained fairly stable at approximately three in ten graduates. The small overall trend between 1997/2001 and 2006/2012 (1.4 percentage points, compare columns 6 and 7) is statistically insignificant; among older workers, overeducation rose by a small amount suggesting some convergence with younger workers. Table 3 shows the top ten four-digit occupations where overeducated

Table 3 Most frequent occupations among overeducated graduates 25-60 years old, 2012

\begin{tabular}{|c|c|c|c|}
\hline Occupation (main job) & Percentage & Cumulative (\%) & Number \\
\hline 4159 other administrative occupations nec & 4.7 & 4.7 & 853 \\
\hline 4122 book-keepers, payroll managers, and wages clerks & 4.3 & 9.0 & 754 \\
\hline 6145 care workers and home carers & 3.8 & 12.8 & 708 \\
\hline 6125 teaching assistants & 3.8 & 16.6 & 709 \\
\hline 7111 sales and retail assistants & 3.5 & 20.1 & 584 \\
\hline 1190 managers and directors in retail and wholesale & 3.4 & 23.4 & 595 \\
\hline 6141 nursing auxiliaries and assistants & 2.6 & 26.0 & 475 \\
\hline 4112 civil service admin officers and assistants & 2.4 & 28.4 & 450 \\
\hline 4215 personal assistants and other secretaries & 2.1 & 30.5 & 384 \\
\hline
\end{tabular}

Note: Relative frequency estimates for the population. Each four-digit occupation is given the same SOC(HE)_GH classification as the three-digit minor group to which it belongs. The last column reports the number of observation occupation in the sample in each four-digit occupation. Source: QLFS Q(1)2012-Q(4)2012 
graduates were located in 2012: often in major group 4 occupations, such as "other administrative occupations". Sales and retail assistants also figure in the list; for those under age 30 , this is the commonest occupation (12\% of those overeducated).

If graduate jobs have grown substantially, what is the proximate source of this growth? The growth of graduate jobs is potentially fuelled by two sources. First, there is the employment expansion in core graduate jobs-those occupations that were and have remained graduate-level occupations. While technological and organisational changes are thought to be the primary source of the evolving demand for skill, it is typically held to be manifested in the asymmetric polarisation of employment. The overall rise in skill demand is often assessed by this structural change alone. However, while it seems likely that structural change in the employment share of occupations will be the main proximate reason for increasing graduate jobs, graduate employment can also grow as a result of occupational upskilling, reflected by a reclassification of some occupations as graduate jobs which previously were non-graduate jobs. Only a few such switchers can contribute strongly to the change in graduate jobs, and in Britain, upgrading occurred with "Social Welfare Associate Professionals", "Managers in Farming, Horticulture, Forestry and Fishing", and "Managers and Proprietors in Other Service Industries", while "Sports and Fitness Occupations" were downgraded.

To investigate the relative importance of these two processes, we carried out a standard decomposition. The change in the proportion of graduate jobs was decomposed into a component that is due to upskilling of occupations and a second component that is due to a change in the employment share of existing graduate jobs. Specifically,

$$
\Delta g l=\sum_{j} \Delta g_{j}\left(\frac{l_{j}^{1}+l_{j}^{2}}{2}\right)+\sum_{j} \Delta l_{j}\left(\frac{g_{j}^{1}+g_{j}^{2}}{2}\right)
$$

where $\Delta g l$ is the growth in employment share of graduate jobs, $g_{j}$ is an indicator $(0,1)$ of whether occupation $j$ is a graduate occupation, and $l_{j}$ is the employment share of occupation $j$ in total employment.

The outcome of this exact decomposition is shown in Fig. 3. It shows that some $69 \%$ $(=100 * 6.6 / 9.6)$ of the growth in total employment in graduate occupations can be

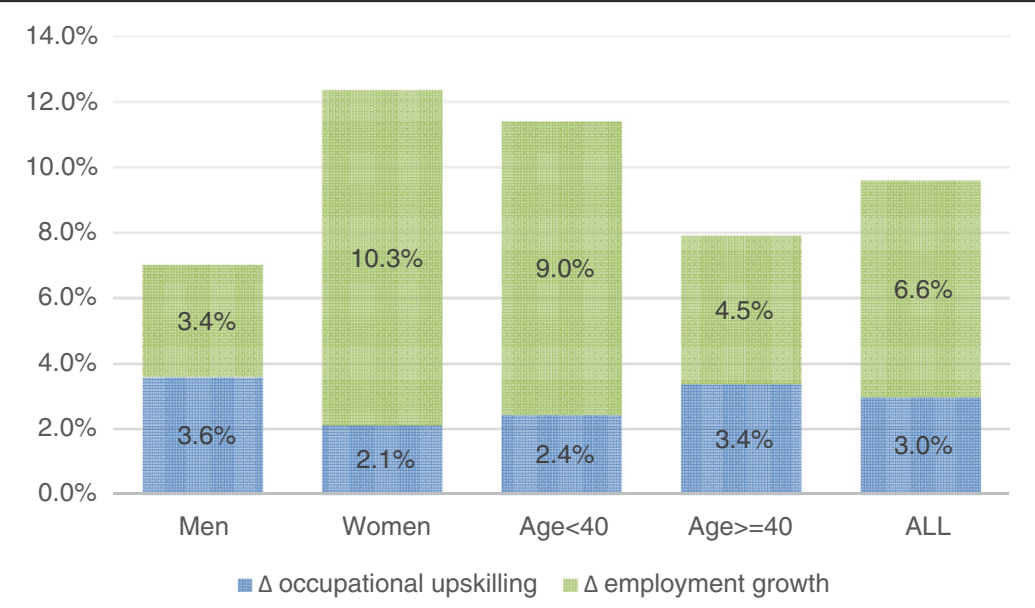

Fig. 3 Decomposing the growing share of graduate jobs. Note: This is an exact decomposition of the change in graduate employment into a component due to employment growth in existing graduate occupations and a component arising from upskilling within occupations. Source: SES 1997-2012 
attributed to expanding employment in the core graduate jobs, with the remaining $31 \%$ due to the increasing number of graduate occupations over time. At least over this period, then, the extent to which graduate employment rose would be underestimated by almost a third if one looked only at the changing occupational composition of employment.

It is of interest to examine the relative importance of the two components for the jobs held by men and women and by younger and older workers. Recent research has shown the importance of occupational upgrading for women in the recent British labour market (Lindley 2015). Consistent with that study, we find that some $83 \%$ of the growing employment in graduate jobs for women is driven by employment expansion in graduate jobs. Underpinning this expansion, prominent examples of fastgrowing occupations where females are concentrated are teaching professionals and health associate professionals, which were, respectively, 88 and 65 \% females in 19972001. By contrast, men have experienced a notably lower level of occupational upgrading: for them, upgrading contributes only just under a half of the rise in graduate employment, the rest being due to upskilling within occupations.

Similarly, one might expect a different source pattern according to age group, since for older workers it is generally more costly to move out of non-growing occupations, given hiring practices (sometimes discriminatory, according to Riach and Rich 2010) that could favour younger workers in the growing skilled occupations, and the importance of occupation-specific and firm-specific skills for older workers (Autor and Dorn 2009). On the other hand, we have no particular priors about how the extent of withinjob upskilling varies with the age of the worker. As Fig. 3 shows, consistent with this expectation, graduate employment growth is greater for those aged under 40. It also turns out that upskilling and reclassification is a slightly more important driver for the jobs held by older workers.

A note of caution is needed with these decompositions and the overall growth rate of graduate jobs. Because of the fuzziness of any dichotomous graduate job classifier, the number of occupations crossing the threshold is inevitably somewhat sensitive, both to sampling variation and to choice of clustering technique. Yet we can be confident that, if medium-term upskilling is measured solely through changes in the employment composition of occupations-the common method-it becomes subject to potentially substantial errors.

Equally, if one were to use one of the existing graduate job classifiers based on occupation major groups, one would obtain a somewhat different picture of the graduate labour market, even if the broad picture of growth in both graduate jobs and the share of graduates remains the same. For example, with the traditional classifier (groups 1 and 2), among men, the proportion doing graduate jobs changed little (and not significantly) from 33 to $35 \%$, and the proportion of male graduates who were overeducated according to this definition rose significantly from 38 to $43 \%{ }^{11}$ Such a difference from our main findings of unchanged overeducation in Table 2 illustrates the importance of the chosen indicator.

\section{The changing wage differentials of matched and mismatched workers}

While graduate overeducation has not, as some feared, rapidly expanded in the decade following 1997/2001, following the continued growth of graduate jobs, the polarising 
structure of employment overall nevertheless gives possible cause to expect some increasing differentiation. Moreover, the end of this period encompassed the disruptions of the Great Recession from 2008. Those attaining graduate jobs might be expected to have fared as well or better than before, given the maintained demand for high-skilled jobs at the end of the period. However, the consequences of overeducation of graduates could have deteriorated. In this section and the next, we study the outcomes. First, we investigate whether the graduate pay premium has become more differentiated. What has happened to the relative rewards of graduates? We examine this question, both with conventional quantile regressions to capture differentiation according to the size of the wage residual (sometimes taken as a signal of unobserved ability) and by investigating changes in the penalty for graduates' overeducation. Second, in the next section, we examine changes in the extent to which overeducation persists.

Table 4 presents a quantile regression analysis of the premium for tertiary education, relative to those at education level 2 (lower secondary). As can be seen, point estimates of the median returns increased for men but barely at all for women. The returns rose at the top quartile, significantly so for men. At the lowest quartile, however, returns fell significantly for women, while remaining steady for men. The net effect is that, for both sexes, there was a widening gap between the returns at the highest and lowest quartiles of the residual distribution. In both cases, the change is statistically significant. The residual is typically attributed to unobserved factors that may include both ability and match quality.

A process of differentiation can also be seen in the evolving penalty for overeducation. To study this, we utilised the SES data and SOC(HE)2000_GH to run Mincer-type wage regressions among graduates for log hourly pay on an overeducation dummy, and

Table 4 Relative returns to tertiary education over lower secondary education at different quartiles of the log wage distribution

\begin{tabular}{clll}
\hline & $p 25$ & $p 50$ & $p 75$ \\
\hline All $(N=13,060)$ & & & \\
P1 $(1997 / 2001)$ & $0.473^{* * *}$ & $0.500^{* * *}$ & $0.510^{* * *}$ \\
P2 (2006/2012) & $(0.0202)$ & $(0.0186)$ & $(0.0195)$ \\
& $0.420^{* * *}$ & $0.538^{* * *}$ & $0.586^{* * *}$ \\
Men $(N=6509)$ & $(0.0250)$ & $(0.0188)$ & $(0.0275)$ \\
P1 (1997/2001) & & & $0.491^{* * *}$ \\
P2 (2006/2012) & $0.392^{* * *}$ & $0.453^{* * *}$ & $(0.0290)$ \\
Women $(N=6551)$ & $(0.0308)$ & $(0.0236)$ & $0.541^{* * *}$ \\
P1 $(1997 / 2001)$ & $0.407^{* * *}$ & $0.531^{* * *}$ & $(0.0410)$ \\
& $(0.0358)$ & $(0.0306)$ & \\
P2 (2006/2012) & & & $0.551^{* * *}$ \\
& $0.519^{* * *}$ & $0.541^{* * *}$ & $(0.0309)$ \\
& $(0.0249)$ & $(0.0254)$ & $0.583^{* * *}$ \\
\hline
\end{tabular}

Note: Reported figures are the marginal effects of tertiary education on log real hourly pay over lower secondary education at the first, second, and third quartiles of the earnings distribution after controlling for age, age squared, sex (pooled model only), dummies for ethnicity (Asian, African, other, missing, and White as reference group), marital status, indicator for dependent children in the household, and a London dummy. Data from SES for the whole workforce in the age bracket $25-60$. All models use survey weights. ${ }^{*} \mathrm{p}<.1 ;{ }^{* *} \mathrm{p}<.05 ;{ }^{* * *} \mathrm{p}<.01$ 
period dummy to capture both trends and any interaction with overeducation, and a set of common control variables (age, age squared, marital status, presence of dependent children, region, survey year, and sex for the pooled model). The findings are shown in Table 5.

Consistent with other studies, the log wage penalty of mismatched (i.e. overeducated) graduates relative to matched graduates was significant and sizable, being 38 log points in 1997-2001. What we are primarily interested in, however, is how this penalty changed: by 2006-2012, it had risen to a hefty 49 log points. The final row summarises how the $\log$ wage penalty changed between periods, both overall and separately by gender. As can be seen from the first row, the penalty increased overall by 11 log points. The increase was similar in magnitude for men and women, though not quite statistically significant for men: it had risen by the end of the period to $45 \log$ points for men and $52 \log$ points for women.

One might ask how this 11-point rising penalty for overeducation is reflected in the changing returns for matched and non-matched graduates (as compared with matched non-graduates). To compute this, we also ran regressions comprising the full sample of graduates and non-graduates. The analysis (not shown here) indicated that the premium for matched graduates over matched non-graduates increased significantly by 5 points, which might be argued to be consistent with the persistence of skill-biased technological change over this period, while at the same time, there was a 6-point significant fall in the premium for mismatched graduates. This pattern of change parallels the changing quartile returns shown in the analysis of Table 4.

The caveat to these analyses, as for other studies in the literature, is that overeducation status may be endogenous, reflecting either heterogeneous skills among graduates or other unobserved factors that also affect pay. Some studies have shown, for example, that workers with lower skill levels-measured by an external indicator such as test performance or math certification-experience a somewhat enhanced risk of being overeducated (Green and McIntosh 2007; McGuinness and Bennett 2007; Chevalier and Lindley 2009). These studies establish that overeducation may be partly a consequence of low skill, but by no means entirely so. In our own conclusions about the changing penalty, we are implicitly assuming that any endogeneity bias in the estimated overeducation penalty did not substantively change between the two periods. ${ }^{12}$

Table 5 Change in log wage penalty for mismatched over matched graduates between 19972001 and 2006-2012

\begin{tabular}{llll}
\hline & $(1)$ & $(2)$ & $(3)$ \\
& All & Men & Women \\
\hline $1997-2001$ & $-0.375^{* * *}$ & $-0.353^{* * *}$ & $-0.406^{* * *}$ \\
& $(0.0297)$ & $(0.0424)$ & $(0.0393)$ \\
$2006-2012$ & $-0.485^{* * *}$ & $-0.448^{* * *}$ & $-0.521^{* * *}$ \\
Change & $(0.0269)$ & $(0.0436)$ & $(0.0289)$ \\
& $-0.110^{* * *}$ & -0.095 & $-0.114^{* *}$ \\
$N$ & $(0.0401)$ & $(0.0609)$ & $(-0.0488)$ \\
\hline
\end{tabular}

Notes: Estimation model: $\ln \left(y_{i}\right)=a_{1} \cdot \mathrm{OE}_{i}+a_{2} \cdot T+a_{3}\left(\mathrm{OE}_{i} \cdot T\right)+X_{i}^{\prime} \beta+e_{i} \cdot y$ is real log hourly pay, OE is the dummy for overeducation, $T$ is a (0/1) time dummy capturing the two periods, and $X$ comprises controls for age, age squared, sex (pooled model only), dummies for ethnicity (Asian, Black, other, missing, and White as reference group), marital status, indicator for dependent children in the household, and a London dummy. The interaction coefficient picks up the change over time in the overeducation wage penalty. ${ }^{*} p<.1 ;{ }^{* *} p<.05 ;{ }^{* *} p<.01$ 
Thus, the prevalence of overeducation might not have altered very much, as the previous analysis of Table 2 shows. Moreover, the wage premium for higher education, where it secures a graduate job, has improved. As expected, however, consequent upon the broader structural changes, the wage differences between matched and mismatched graduates have become more marked. If one were to view the chances of being overeducated, conditional on graduation, as to a considerable extent a matter of chance, then the risks have also increased.

\section{The persistence of skills mismatch}

We now turn to the dynamics of graduate skills mismatch and ask whether the experience of overeducation in recent years has been subject to a substantial and changing level of state dependency. Whether graduate overeducation is a matter of concern (private or public) depends in part on its persistence. Thus, policy is unlikely to be called on if in most cases overeducated graduates remain in this state only for short periods. If, however, most become stuck in non-graduate jobs-perhaps due to lack of workplace learning opportunities-the efficiency, welfare, and policy implications become greater. Such concerns are augmented where non-employed graduates gaining employment transition to non-graduate jobs.

Unfortunately, previous studies in a range of countries have found that underutilisation of either qualifications or skills is persistent to a large extent, though with some variation over the type of education and age group (Sloane et al. 1999; Carroll and Tani 2013; Kiersztyn 2013; Mavromaras and McGuiness 2012). Some specifically test and reject the "career mobility" interpretation of overeducation, under which overeducation is expected to be temporary (Korpi and Tåhlin 2009; Baert et al. 2013).

At the end of the 1990s, Britain's mismatched graduates faced a steadily growing economy and a buoyant labour market with falling unemployment. This outlook contrasts with that confronting graduates from 2006 to 2012, most of which was dominated by the Great Recession. By that time, as seen in Table 2, the aggregate balance between graduate jobs and the stock of graduates had slipped from slightly positive to slightly negative territory. Moreover, economic stagnation and rising unemployment indicate fewer new job openings, hence fewer opportunities for overeducated graduates to progress to a graduate job, as well as fewer opportunities for those out of work to find graduate jobs. We hypothesised, therefore, first that the state of graduate overeducation would have become more difficult to escape from than it had been between 1997 and 2001 and second that for those graduates not in work, more would find themselves transitioning into non-graduate jobs.

To investigate how persistent is graduate overeducation, we used ISCO(HE) 88 _GH to describe graduates' transitions between work statuses, using an unbalanced panel of graduates in the BHPS/UKHLS in the age bracket 25 to 60 years during the years 1997-2001 and 2006-2012. We considered three states: non-employment, in work but mismatched (overeducated), and in work in a graduate job. Table 6 presents year-onyear transition matrices. ${ }^{13}$

It can be seen that, among men, just over $11 \%$ of mismatched workers found a matched job 1 year later over 1997-2001: a significant but small minority. Remarkably, this figure had not changed by the second period. Similarly, persistence for female 
Table 6 Annual transitions between labour market states, 1997-2001 and 2006-2012 (in \%)

\begin{tabular}{|c|c|c|c|c|c|c|}
\hline \multirow{3}{*}{$\begin{array}{l}\text { Previous labour market } \\
\text { position }\end{array}$} & \multicolumn{6}{|c|}{ Current labour market position } \\
\hline & \multicolumn{3}{|l|}{ 1997-2001 } & \multicolumn{3}{|l|}{$2006-2012$} \\
\hline & Non-employed & Mismatched & Matched & Non-employed & Mismatched & Matched \\
\hline \multicolumn{7}{|l|}{ Men } \\
\hline Not in work & 66.5 & 8.8 & 24.7 & 77.4 & 6.2 & 16.4 \\
\hline Mismatched & 2.9 & 85.8 & 11.3 & 3.6 & 85.0 & 11.4 \\
\hline Matched & 2.8 & 2.3 & 94.9 & 2.5 & 2.4 & 95.1 \\
\hline \multicolumn{7}{|l|}{ Women } \\
\hline Not in work & 71.3 & 8.6 & 20.1 & 69.8 & 12.3 & 18.0 \\
\hline Mismatched & 11.1 & 80.9 & 8.1 & 8.9 & 83.2 & 7.9 \\
\hline Matched & 7.1 & 2.0 & 90.9 & 5.7 & 2.8 & 91.5 \\
\hline \multicolumn{7}{|l|}{ Ages 25-39 } \\
\hline Not in work & 54.9 & 11.3 & 33.9 & 57.0 & 13.4 & 29.6 \\
\hline Mismatched & 6.7 & 80.1 & 13.2 & 9.3 & 78.0 & 12.8 \\
\hline Matched & 4.4 & 3.1 & 92.5 & 5.3 & 2.9 & 91.8 \\
\hline \multicolumn{7}{|l|}{ Ages 40-60 } \\
\hline Not in work & 79.4 & 7.0 & 13.6 & 81.0 & 9.0 & 10.0 \\
\hline Mismatched & 6.3 & 87.8 & 5.9 & 5.2 & 87.8 & 7.0 \\
\hline Matched & 5.0 & 1.3 & 93.7 & 3.3 & 2.5 & 94.2 \\
\hline$N$ & 785 & 1025 & 3188 & 1291 & 1821 & 5632 \\
\hline
\end{tabular}

Note: Transition matrix based on data from an unbalanced panel of economically active and inactive graduates aged 25-60 years from BHPS waves 7-18 and UKHLS waves 2-4

graduates remained at above $80 \%$. Comparing the younger and older age groups, the chances of escaping mismatch status were greater for the young (13\%) than for the old (6\%), but again, these figures barely changed between the periods. Thus, our first hypothesis is not confirmed: the escape velocity from mismatch status, already low in 1997-2001, did not decrease further by 2006-2012. Even though this period was dominated by a major recession, there remained a sufficient turnover of graduate jobs to offer some opportunities for graduates to move to better jobs.

Consistent with the second hypothesis, however, the table shows a deterioration in the prospects for non-employed graduates. Especially for men, fewer moved into employment a year later and there was a substantive decline, from 25 to $16 \%$, in the proportion of non-employed graduates who moved into graduate jobs. Since the decline in transitions to non-graduate jobs was much smaller, it is apparent that relatively fewer graduates gaining employment were moving into graduate jobs.

One might ask whether this decline is explained by compositional changes in the characteristics of male workers between periods. Accordingly, we also estimated a model of the transition controlling for demographic characteristics and for initial conditions; the results are shown in Table 7. The findings suggest that part of the transition into graduate jobs is indeed linked to demographic and other individual characteristics. However, the fall between periods (shown in the third row) is significant, and its magnitude is even enhanced after controls and initial conditions are included in the model. We conclude that there was a genuine decline in the ability of graduates, once out of employment, to move into graduate jobs. 
Table 7 Change in the probability for male graduates to move from non-employment to graduate work: marginal effects of non-employment in $(t-1)$ on graduate work in $t$

\begin{tabular}{llll}
\hline$t$ & $(1)$ & $(2)$ & $(3)$ \\
\hline $1997-2001$ & $-0.521^{* * *}$ & $-0.486^{* * *}$ & $-0.166^{* * *}$ \\
$2006-2012$ & $(0.0283)$ & $(0.0303)$ & $(0.0417)$ \\
& $-0.629^{* * *}$ & $-0.600^{* * *}$ & $-0.309^{* * *}$ \\
Difference & $(0.0219)$ & $(0.0242)$ & $(0.0405)$ \\
& $-0.108^{* * *}$ & $-0.113^{* * *}$ & $-0.142^{* * *}$ \\
Demographics & $(0.0358)$ & $(0.0383)$ & $(0.0522)$ \\
Initial conditions & & $X$ & $X$ \\
$N$ & & & $X$ \\
\hline
\end{tabular}

Note: Results from a multinomial probit model: $P($ Jbstat $)=a_{1} *$ lue $+a_{2} *$ period $+a_{3}$ (lue $*$ period $)+\beta X+e$. Marginal effects calculated for the transition from lagged non-employment to graduate work. Model (2) includes dummy for ages $>40$, non-White ethnicity, married, children under 16 in the household, and residence in London or the SouthEast. Model (3) adds the initial value of the dependent variable and within-panel means of time-varying variables as well as the initial values of time-varying values to the list of covariates to address the initial condition problem and correlations between observed and unobserved individual characteristics following Wooldridge (2005) and Rabe-Hesketh and Skrondal (2013). Standard errors in parentheses. ${ }^{*} p<.1 ;{ }^{* *} p<.05 ;{ }^{* * *} p<.01$

\section{Conclusions}

Using a new and validated method for classifying occupations into graduate jobs or non-graduate jobs, this paper has investigated changes in the graduate labour market in Britain between 1997/2001 and 2006/2012. In addition to the method and outcome indicator of the classification process, the paper contributes novel evidence on a number of fronts:

i. There was a very substantial growth, from 32 to $41 \%$, in the share of graduate jobs in Britain. Overall, employment growth of existing graduate occupations (at the minor group level) contributed most to the graduate job growth, the rest being due to upskilling and consequent reclassification of a small number of jobs as graduate.

ii. While there was slightly greater growth in the supply of graduates, from 30 to $42 \%$ of the employed labour force, the overall prevalence of overeducated graduates was stable at around $30 \%$. In particular, the massive influx of graduates into the labour force in the age bracket 25-39 years was absorbed with no increase in overeducation.

iii. The returns to graduation became more dispersed, with those at the upper quartile of the residual distribution increasing, while those at the lowest quartile have fallen.

iv. Similarly, the premium for matched graduates increased, while that for mismatched graduates decreased, with the result that the wage gap between matched and mismatched graduates-the overeducation penalty-increased by 11 log points.

v. There has been no change in the degree of state dependence in overeducation status after 1 year, which has remained high. However, for non-employed male graduates moving into employment, the chances of entering a graduate job decreased.

Both our new classifier of graduate jobs and the concept itself have some limitations which we have noted. The indicator depends on the reliability of self-reported task measures. The methodology can only be followed where suitable data sets with task 
and educational requirement data are available and where cell sizes are reasonable at least at the three-digit level; accordingly, while the classification can be applied to any contemporaneous data that includes the same occupation codes, the classification methodology is specific to each task-based data set. The classification is not as simple as, for example, describing graduate jobs through occupational major groups. Nevertheless, unlike expert-based evaluations of occupations, the statistically driven methodology is transparent and our classifier could be reproduced by other researchers (our data is available on the UK Data Archive). The indicator performs better than or as well as other available indicators in criterion validity tests.

The concept of a graduate job is also, as discussed in Section 2, somewhat fuzzy. Nevertheless, it is widely deployed in public discourse, and the analytical value of any graduate job classifier should be judged from its potential usefulness for understanding change in graduate labour markets. A knowledge of the distribution and trend in graduate jobs, as well as their varied pay, helps to inform the conditions surrounding private investment in tertiary human capital-something that is especially useful at a time of rising uncertainty about future skill demands of technology and (in the case of Britain) of increasing student debt following the raising of tuition fees in 2012 to $£ 9000$.

In this context, $\mathrm{SOC}(\mathrm{HE}) \_\mathrm{GH}$ appears to yield a plausible analysis of changes in the first decade of this century, which can complement the picture obtained from calculations of rates of return. The growth of graduate jobs kept up with the growth of graduates, but the differentiation trend would appear to be raising the risks associated with an investment in college, altering thereby the potential contribution of growing tertiary education to raising social mobility. The demonstrated risks are embodied in two forms: the chances of being in the lower quartile of the (graduate) pay distribution and the chances of being-and remaining-overeducated with its accompanying wage penalty. While these are separate risks, they are related by the fact that overeducated graduates are more likely to be in the lower parts of the distribution. Moreover, both manifestations of risk show increases, consistent with the macro-level drivers noted in the introduction: the relative diminution of middle-level jobs over the long term and the effect of the Great Recession. And, while we found no structural change in the skills used in graduate jobs over the period, massification of higher education might itself be leading to increasing heterogeneity in graduate skills.

The findings also demonstrate how estimates of upskilling derived from changing occupational composition could be downward-biased in a decade where there has been some net upgrading of occupations and vice versa if there develops a downskilling trend as has been suggested for the USA (Beaudry et al. 2016). An adequate graduate job classifier, using the methodology proposed here, will help to understand both the distribution of high-skills demand and its growth. With the ongoing massification of higher education worldwide, the supply of graduates will grow for at least the next two decades, but the expansion of graduate jobs is more uncertain, given uncertainty over future technologies, including predictions that the so-called fourth industrial revolution may radically alter the demand for labour. A good understanding of graduate labour markets is likely therefore to become even more important. Trends and distributions of graduate jobs could be analysed for any population where suitable task-based and educational requirement data are available, such as Germany or the USA. If the OECD's 
Survey of Adult Skills is repeated with sufficient consistency after a decade, an analysis of the trend in graduate jobs in multiple countries would be highly informative.

\section{Endnotes}

${ }^{1}$ Here and throughout, we refer to "skills" in a broad sense, to embrace knowledge and attitudes as well as technical capabilities (Green 2013, Chap. 2).

${ }^{2}$ The term "job" is in this paper described by the three-digit occupation group (rather than the individual contracts that employers and employees enter into). See Green and Henseke (2014) for a parallel approach using unit groups at the four-digit level. The alternative would be to treat each individual employment contract as a job. Using individual-level data, some studies classify individual jobs according to whether graduates perceive their skills are being utilised (Smetherham 2006); such indices are inherently not transferable to other data sets.

${ }^{3}$ For this reason, some researchers derive fuzzy indicators of educational mismatch, derived from latent variable analyses (Betti et al. 2011). Beyond the critique of existing indicators developed here, a pure human capital approach might question the use of any demand-side concept such as "graduate job", given non-zero substitutability in production; we take the view that demand-side concepts, given their explanatory power, complement the human capital approach.

${ }^{4}$ We have added the suffix "EP" in order to distinguish this classifier from the one we develop below.

${ }^{5}$ Full details of these surveys, which have all been placed in the UK Data Archive, can be found at Ashton and Felstead (1998), Felstead et al. (2002, 2007), and Felstead and Green (2008) and for the 2012 survey in Felstead et al. (2013) at http://www.cardiff.ac.uk/ socsi/ses2012/.

${ }^{6}$ http://www.ons.gov.uk/ons/index.html

${ }^{7} \mathrm{~A}$ special situation arises in a few cases where workers state that a post-graduate level is required to get the job, but not necessary to perform it. It is plausible to assume that a qualification at first-degree level or similar will be nonetheless essential or fairly necessary to carry out the job tasks. We therefore replace the value of the binary variable with the value 1 in such situations.

${ }^{8}$ It is for this reason that the OECD Survey of Adult Skills used frequencies for the response frames to task questions, since these were held to be less susceptible to cultural/cross-national bias than an "importance" scale.

${ }^{9}$ The threshold is taken to be time invariant, on the assumption, implicit in most research on returns to higher education, that the standard of higher education has not changed over the time period. While the latter is hard to test, absent skills data for graduates in the two periods, we included a period dummy in the relationship that was computed at stage 2 between the GSR and the tertiary educational requirement. The result implied that there has been no substantive or significant change in the level of skills that employers expect when requiring their employees to have degrees.

${ }^{10}$ We also explored alternative approaches to derive an empirical classification of graduate jobs (see Green and Henseke 2014 for details). These fared only slightly worse in the validation procedure than SOC(HE)_GH.

${ }^{11}$ Using the Gottschalk-Hansen classification approach also found a decrease in the prevalence of graduate jobs and a rise in overeducation during the 2000s. 
${ }^{12}$ As one check, by including a period dummy, we tested whether there was a change, between time periods, in the relationship between required skills and the GSR index used to derive the classifier. There was no significant change.

${ }^{13}$ Moving to dependent interviewing caused a mid-2000s break in year-on-year occupational mobility estimates from BHPS (Perales 2014). Following Longhi and Brynin (2010) for period 1, we classified occupational switches as genuine only where the current job started after the last interview.

\section{Additional file}

Additional file 1: This additional file gives further details of the procedures used for generating the graduate job classifier (SOC(HE)_GH) used in the paper, lists graduate and non-graduate jobs within major occupation groups 1-4, and presents additional criterion validity tests of SOC(HE)2010_GH against existing graduate job indicators used elsewhere.

\section{Competing interests}

The IZA Journal of Labor Policy is committed to the IZA Guiding Principles of Research Integrity. The authors declare that they have observed these principles.

\section{Acknowledgements}

We would like to thank Claire Callender for her helpful comments on an earlier draft of the paper. We are also thankful to the anonymous referees and editor for the useful remarks.

Responsible editor: David Neumark

\section{Funding}

This study was funded by a grant to the LLAKES Centre, UCL Institute of Education, by the UK Commission for Employment and Skills through its strategic partnership with the Economic and Social Research Council.

Received: 4 February 2016 Accepted: 20 May 2016

Published online: 26 July 2016

\section{References}

Acemoglu D, Autor D (2011) Skills, tasks and technologies: implications for employment and earnings. Handb Labor Econ 4:1043-1171

Allen J, Van der Velden R (Eds) (2011) The flexible professional in the knowledge society: New challenges for higher education. Springer Science \& Business Media

Altonji JG, Blom E, and Meghir C (2012). Heterogeneity in human capital investments: high school curriculum, college major, and careers (No. w17985). National Bureau of Economic Research.

Ashton D, Felstead A (1998) Organisational characteristics and skill formation in Britain: is there a link?, Working Paper 22. Leicester University, Centre for Labour Market Studies

Autor D, Dorn D (2009) The skill content of jobs and the evolution of the wage structure-this job is "getting old": measuring changes in job opportunities using occupational age structure. Am Econ Rev 99(2):45

Autor DH, Levy F, Murnane RJ (2003) The skill content of recent technological change: an empirical exploration. Q J Econ 118(4):1279-1333

Baert S, Cockx B, Verhaest D (2013) Overeducation at the start of the career: stepping stone or trap? Labour Econ 25 $123-140$

Beaudry P, Green DA, Sand BM (2016) The great reversal in the demand for skill and cognitive tasks. J Labor Econ 34(1, pt 2):S199-\$247

Betti G, D'Agostino A, Neri L (2011) Educational mismatch of graduates: a multidimensional and fuzzy indicator. Soc Indic Res 103(3):465-480

Bukodi E, Goldthorpe J (2011) Social class returns to higher education: chances of access to the professional and managerial salariat for men in three British birth cohorts. Longit Life Course Stud 2(2):185-201

Cardoso AR (2007) Jobs for young university graduates. Econ Lett 94(2):271-277

Carroll D, Tani M (2013) Over-education of recent higher education graduates: new Australian panel evidence. Econ Educ Rev 32:207-218

Chevalier A, Lindley J (2009) Overeducation and the skills of UK graduates. J R Stat Soc Ser A Stat 172(2):307-337

Dustmann C, Ludsteck J, and Schönberg U (2009). Revisiting the German wage structure. Q J Econ, 124(2):843-881

Elias P, McKnight A (2001) Skill measurement in official statistics: recent developments in the UK and the rest of Europe. Oxf Econ Pap 53(3):508-540

Elias P, Purcell K (2004a) Is mass higher education working? Evidence from the labour market experiences of recent graduates. Natl Inst Econ Rev 190(1):60-74

Elias P, Purcell K (2004b) SOC (HE): a classification of occupations for studying the graduate labour market, Research Graduate Careers Seven Years On, Research Paper., p 6

Elias P, Purcell K (2013) Classifying graduate occupations for the knowledge society, Institute for Employment Research. University of Warwick. Futuretrack working paper, 5

Everitt BS, Landau S, Leese M (2001) Cluster analysis. Arnold, A member of the Hodder Headline Group, London 
Felstead A, Green F (2008) Skills at work in Scotland, 1997 to 2006. Glasgow, Scottish Enterprise

Felstead A, Gallie D, Green F (2002) Work skills in Britain 1986-2001. DfES Publications, Nottingham, p 160

Felstead A, Gallie D, Green F, Zhou Y (2007) Skills at work, 1986-2006. University of Oxford, SKOPE

Felstead A, Gallie D, Green F, Inanc H (2013) Skills at work in Britain. Centre for Learning and Life Chances in Knowledge Economies and Societies, Institute of Education, London

Fernández-Macías E (2012). Job polarization in Europe? Changes in the employment structure and job quality, 1995-2007. Work and Occupations, 0730888411427078.

Figueiredo H, Teixeira P, Rubery J (2011) Is mass higher education working?., An Update and a Reflection on the Sustainability of Higher Education Expansion in Portugal, (No. 14)

Figueiredo H, Teixeira P, Rubery J (2013) Unequal futures? Mass higher education and graduates' relative earnings in Portugal, 1995-2009. Appl Econ Lett 20(10):991-997

Gathmann C, Schönberg U (2010) How general is human capital? A task-based approach. J Labor Econ 28(1):1-49

Goos M, Manning A, Salomons A (2014) Explaining job polarization: routine-biased technological change and offshoring. Am Econ Rev 104(8):2509-2526

Gottschalk P, Hansen M (2003) Is the proportion of college workers in noncollege jobs increasing? J Labor Econ 21 (2):449-471

Green F (2012) Employee involvement, technology and evolution in job skills: a task-based analysis. Ind Labor Relat Rev 65(1):36-67

Green, F. (2013). Skills and skilled work: an economic and social analysis. Oxford University Press, Paris

Green F, Henseke G (2014) The changing graduate labour market: analysis using a new indication of graduate jobs, LLAKES Research Paper., p 50

Green F, James D (2003) Assessing skills and autonomy: the job holder versus the line manager. Hum Resour Manag J 13(1):63-77

Green F, McIntosh S (2007) Is there a genuine under-utilization of skills amongst the over-qualified? Appl Econ 39(4):427-439

Green F, Zhu Y (2010) Overqualification, job dissatisfaction, and increasing dispersion in the returns to graduate education. Oxf Econ Pap 62(4):740-763

Green A, Green F, Pensiero N (2015) Cross-country variation in adult skills inequality, Why are the Anglophone Countries so unequal? Comparative Education Review. Autumn

Groom B (2013) Half of recent graduates are in non-graduate jobs, Financial Times, November $19^{\text {th }}$

Hoekstra M (2009) The effect of attending the flagship state university on earnings: a discontinuity-based approach. Rev Econ Stat 91(4):717-724

Jürges H (2007) True health vs response styles: exploring cross-country differences in self-reported health. Health Econ 16(2):163-178

Kiersztyn A (2013) Stuck in a mismatch? The persistence of overeducation during twenty years of the post-communist transition in Poland. Econ Educ Rev 32:78-91

Korpi T, Tåhlin M (2009) Educational mismatch, wages, and wage growth: overeducation in Sweden, 1974-2000. Labour Econ 16(2):183-193

Kuczera M, Field S, Windisch HC (2016) Building skills for all: a review of England. Policy insights from the Survey Of Adult Skills. OECD, Paris

Lindley J (2015) Gender differences in job quality. In: Green F, Felstead A, Gallie D (eds) Unequal Britain at work. The evolution and distribution of job quality. Oxford University Press, Oxford, pp 42-61

Lindley JK, Machin S (2014) Spatial changes in labour market inequality. J Urban Econ 79:121-138

Little B, Braun E, Tang WY (2008) Competences possessed and required by European graduates REFLEX Report to HEFCE No 4

Longhi S, Brynin M (2010) Occupational change in Britain and Germany. Labour Econ 17(4):655-666

Lui HK, Suen W (2005) The shrinking earnings premium for university graduates in Hong Kong: the effect of quantity or quality? Contemp Econ Policy 23(2):242-254

Machin S, McNally S (2007) Tertiary education systems and labour markets, Education and Training Policy Division, OECD

Macmillan, L., Tyler, C., and Vignoles, A. (2015). Who gets the top jobs? The role of family background and networks in recent graduates' access to high-status professions. I Soc Policy 44(03):487-515

Martins PS, Pereira PT (2004) Does education reduce wage inequality? Quantile regression evidence from 16 countries. Labour Econ 11(3):355-371

Mason G, Williams G, Cranmer S (2009) Employability skills initiatives in higher education: what effects do they have on graduate labour market outcomes? Educ Econ 17(1):1-30

Matthes B, Christoph B, Janik F, Ruland M (2014) Collecting information on job tasks_-an instrument to measure tasks required at the workplace in a multi-topic survey. J Lab Mark Res 47(4):273-297

Mavromaras K, McGuinness S (2012) Overskilling dynamics and education pathways. Econ Educ Rev 31(5):619-628

McGuinness S (2006) Overeducation in the labour market. J Econ Surv 20(3):387-418

McGuinness S, Bennett J (2007) Overeducation in the graduate labour market: a quantile regression approach. Econ Educ Rev 26(5):521-531

Milburn A (2009) Unleashing aspiration: the final report of the panel on fair access to the professions

Neumark D, Johnson H, Mejia MC (2013) Future skill shortages in the U.S. economy? Econ Educ Rev 32:151-167

O'Leary NC, Sloane PJ (2014) Too many graduates? An application of the Gottschalk-Hansen model to young British graduates between 2001-2010, IZA Discussion Paper., p 8413

OECD. (2013). OECD Skills Outlook 2013: first results from the Survey of Adult Skills. OECD Publishing, Paris

ONS (2013) Full report—graduates in the UK labour market 2013

Perales F (2014) How wrong were we? Dependent interviewing, self-reports and measurement error in occupational mobility in panel surveys. Longit Life Course Stud 5(3):299-316

Pierre G, Sanchez Puerta ML, Valerio A, Rajadel T (2014) STEP skills measurement surveys: innovative tools for assessing skills

Rabe-Hesketh S, Skrondal A (2013) Avoiding biased versions of Wooldridge's simple solution to the initial conditions problem. Econ Lett 120(2):346-349 
Riach PA, Rich J (2010) An experimental investigation of age discrimination in the English labor market, Annals of Economics and Statistics/Annales d'Économie et de Statistique., pp 169-185

Salvatori A (2015) The anatomy of job polarisation in the UK., IZA Discussion Papers, (No. 9193)

Scurry T, Blenkinsopp J (2011) Under-employment among recent graduates: a review of the literature. Pers Rev 40(5):643-659

Sloane PJ, Battu H, Seaman PT (1999) Overeducation, undereducation and the British labour market. Appl Econ 31(11):1437-1453

Smetherham C (2006) Firsts among equals? Evidence on the contemporary relationship between educational credentials and the occupational structure. J Educ Work 19(1):29-45

Sullivan P (2009) Estimation of an occupational choice model when occupations are misclassified. J Hum Resour 44(2):495-535

University of Essex (2010) Institute for Social and Economic Research, British Household Panel Survey: waves 1-18, 1991-2009 [computer file], 7th edn. UK Data Archive [distributor], Colchester, Essex, SN: 5151

University of Essex (2014) Institute for Social and Economic Research and NatCen Social Research, Understanding Society: waves 1-4, 2009-2013 [computer file], 6th edn. UK Data Archive [distributor], Colchester, Essex, SN: 6614

Verdugo RR, and Verdugo NT (1989). The impact of surplus schooling on earnings: some additional findings. J Hum Resour, 24(4):629-643

Wilton N (2012) The impact of work placements on skills development and career outcomes for business and management graduates. Stud High Educ 37(5):603-620

Wooldridge JM (2005) Simple solutions to the initial conditions problem in dynamic, nonlinear panel data models with unobserved heterogeneity. J Appl Econ 20(1):39-54

Submit your manuscript to a SpringerOpen ${ }^{\circ}$ journal and benefit from:

- Convenient online submission

- Rigorous peer review

- Immediate publication on acceptance

- Open access: articles freely available online

- High visibility within the field

- Retaining the copyright to your article

Submit your next manuscript at $>$ springeropen.com 